\title{
Transparencia pública en la regeneración democrática: La necesidad de visibilizar las agendas institucionales en España
}

\author{
Marta Méndez Juez* \\ Recibido: 06/02/2016 / Aceptado: 15/03/2017
}

Resumen. En la actualidad, es necesario repensar nuestro pacto de convivencia pacífica para suplir la falta de confianza de los ciudadanos en las instituciones político-administrativas. Un sistema democrático avanzado no puede funcionar sin transparencia y, por ende, sin que se asegure el pleno ejercicio del derecho ciudadano a la información pública. Tal derecho, entendido desde la obligación a la transparencia activa de datos por parte de las instituciones, precisa que las fuentes suministradoras de información pública difundan al máximo nivel posible los recursos que poseen. La posibilidad de que los ciudadanos tengan acceso al contenido de las agendas gubernamentales produce un efecto positivo en dos direcciones, ya que, por una parte, vincula a los ejecutivos en el fiel cumplimiento de sus programaciones y, por otra parte, propicia que la sociedad controle la idoneidad y eficacia de la acción gubernamental.

Palabras clave: Democracia; Transparencia; Agenda institucional; Legislación; Comunidades Autónomas.

\section{Transparency in the democratic regeneration: The need to make visible the institutional agendas in Spain}

\begin{abstract}
Nowadays, it is necessary to rethink our peaceful coexistence pact to fill the lack of trust of citizens in political-administrative institutions. An advanced democratic system can not function without transparency and, therefore, without ensuring the full exercise of the citizen's right to public information. This right, understood from the obligation to the active transparency of data by the institutions, it requires that the sources of public information disseminate the resources they possess to the highest possible level. The possibility that citizens have access to the content of institutional agendas has a positive effect in two directions; on the one hand, it links executives in the faithful fulfillment of their schedules and, on the other hand, it favors that society control to the suitability and effectiveness of government action.
\end{abstract}

Keywords: Democracy; Transparency; Institutional Agenda; Legislation; Autonomous Communities.

Sumario. 1. Introducción. 2. Transparencia pública en la regeneración democrática. 3. La obligación institucional a la difusión activa de información pública. 4. La regulación de las agendas institucionales en las leyes de transparencia pública españolas. 4.1. ¿Qué es la agenda institucional? 4.2. Las agendas institucionales en la normativa autonómica. 5. Conclusiones. Bibliografía.

* Universidad de Burgos

mmjuez@ubu.es 
Cómo citar: Mendez Juez, M., «Transparencia pública en la regeneración democrática: La necesidad de visibilizar las agendas institucionales en España», en Cuadernos de Gobierno y Administración Pública 4-1, 89-105.

\section{Introducción}

Para hablar de una democracia de ciudadanía, es requisito imprescindible garantizar a los ciudadanos el ejercicio de sus derechos civiles (garantías contra la opresión), de sus derechos políticos (formar parte de las decisiones públicas) y de sus derechos sociales (acceso de todos al bienestar). La grave y persistente crisis económica ha puesto en evidencia la fragilidad del sistema político, produciendo este hecho una fuerte polarización en la sociedad civil y erosionando la confianza ciudadana en sus instituciones. Además, las desigualdades -ya sean económicas, políticas, culturales, étnicas, de género, etc.-, refuerzan los factores negativos de las democracias de forma y erosionan las instituciones.

El expresidente de la República Oriental del Uruguay, Julio María Sanguinetti, afirma que en democracia: "la conciencia alerta es el único estado de ánimo para que la democracia siga su vida, adaptándose a los tiempos. Ella permanece, después de todo, como la más revolucionaria de las ideas y, por lo mismo que siempre inacabada, la más desafiante" (PNUD, 2004: 199). Por eso, resulta muy necesario que en el imaginario social se suscite el debate y se aporten ideas para dar nuevo ser a la democracia que se degeneró, restablecerla o mejorarla ${ }^{1}$. La regeneración democrática no es más que repensar el pacto de convivencia pacífica, preguntarnos quién ha firmado esto por mí en democracia, de recordar a los decisores públicos que representan el corazón de la autoridad y del poder democrático y que deben evitar los despropósitos verbales y las fútiles cuestiones de interpretación de los asuntos de interés general, para centrarse en su resolución (Saramago, 2004: 54).

Y, precisamente, "el fortalecimiento de las democracias consolidadas requiere de estrategias para la consolidación de prácticas de acceso a la información pública y fomento de la transparencia" (Aldeguer Cerdá, 2013: 343). Por eso, una de las prioridades en las agendas de los gobiernos y uno de los elementos que suscita mayor interés mediático, es la transparencia pública. Entendida como principio vertebrador de cualquier Estado, la transparencia pública acerca las instituciones a los ciudadanos y permite que éstos confíen en los centros de decisión política, que participen en la definición e implementación de las acciones gubernamentales, que evalúen el rendimiento de éstas y de los responsables al frente de las estructuras de poder o que crean en quiénes les dirigen y en la manera de hacerlo.

El presente estudio tiene como finalidad resaltar la importancia de la transparencia activa en cualquier sistema democrático, profundizar en el estudio de las agendas gubernamentales como mecanismos de planificación institucional y supervisión ciudadana, analizar cómo se regulan dichas agendas en las leyes de transparencia españolas y proponer algunas líneas de mejora que renueven la práctica diaria de las Administraciones Públicas en su progresiva tarea de apertura y modernización.

1 Tal y como aparece reflejado en el Diccionario de la Real Academia de la Lengua Española. 


\section{Transparencia pública en la regeneración democrática}

La transparencia posibilita que los ciudadanos estén al día del qué, cómo y para qué se llevan a cabo las actuaciones del poder público, que confíen en los centros de decisión política, que participen en la definición e implementación de las acciones gubernamentales, que evalúen el rendimiento de éstas y de los responsables al frente de las estructuras de poder, que crean en quiénes les dirigen y en la manera de hacerlo, que retomen la certidumbre en un escenario de continuo cambio y adaptación.

De igual modo, la transparencia es exigible para cualquier empleado que desempeñe una función o ejerza un servicio público, por cuanto se pide que éste actúe con la máxima diligencia y profesionalidad en su trabajo y con la mayor dispensa al ciudadano, motivos que hacen necesaria la apertura en la gestión y en la dirección de los órganos públicos a los que quedan adscritos. La obligación de clarificar sus actuaciones, de informar sobre sus decisiones, de mostrar los resultados de sus cometidos trae consigo necesidades conexas de simplificación organizativa, de reducción de cargas burocráticas, de reforma y modernización públicas. Es labor de las instituciones mejorar el servicio que prestan al ciudadano, generando confianza $\mathrm{y}$ apertura en dicho proceso.

En la actualidad, una de las prioridades en las agendas de los gobiernos y uno de los elementos que suscita mayor interés mediático, es la transparencia pública. Este concepto tan manido y de latente profusión, pese a no ser reconocido expresamente en el constitucionalismo español, no resulta novedoso en la Historia de las civilizaciones. Autores ilustrados como Jeremy Bentham sostuvieron que la Transparencia Pública quedaba íntimamente unida a la libertad de expresión y de imprenta de que goza todo ser humano, tal y como quedó reflejado en el artículo 11 de la Declaración de Derechos del Ciudadano de 1789.

Autores como Bellver Vázquez-Dodero (2007), adoptan una definición de transparencia sugerida ya por Florini (1999), que considera a ésta como: "la divulgación, por parte de las instituciones, de información que es relevante para evaluarlas". Por tanto, si para parte de la doctrina lo verdaderamente relevante es conseguir, a través de la transparencia, una finalidad política de participación social, para otros, lo más importante es que, con dicha información, los ciudadanos sean capaces de evaluar el rendimiento de las instituciones y lograr su confianza en ellas, legitimando con ello la labor que realizan para la cohesión de las sociedades. En este sentido, Garde Roca (2004: 13) señala que evaluar las instituciones supone interpretar la información obtenida de ellas, estableciendo visiones de la realidad y suministrando resultados basados en "evidencias que sean creíbles, fiables y útiles", de modo que esta labor permita la incorporación oportuna de los hallazgos, recomendaciones y lecciones en los procesos de adopción de decisiones en la vida política. Por ello, la transparencia puede ser vista como un medio específico para evaluar a los poderes públicos desde "el proceso sistemático de recolección y análisis de la información, destinado a describir la realidad y emitir juicios de valor sobre su adecuación a un patrón o criterio de referencia establecido como base para la toma de decisiones".

Pese a que la transparencia, arraigada en el derecho a la información, debiera ser una característica propia de las instituciones de poder público, vemos cómo no suele manifestarse como una característica concreta de éstas, sino que son más proclives a la opacidad y al secreto de sus actuaciones. Pasquier y Villeneuve (2007), explican algunas de las resistencias a la apertura informativa de las organizaciones públi- 
cas: a) por una parte, observan una causa de comportamiento general, cuál es la cultura del secretismo que proviene de la tradición histórica de muchos Estados; b) otra de las causas, de carácter institucional, estriba en la cultura burocrática de dichas organizaciones, pues éstas, para evitar admitir sus errores y mantener su ventaja comparativa respecto del resto de entes, tienden a no difundir sus datos; c) una tercera causa para la resistencia informativa de las instituciones es de tipo política, debido a la preocupación por la seguridad y la protección de datos en los Estados; y d) la cuarta y última de las causas, de naturaleza organizativa, que señalan los autores, deriva del hecho de que éstas están poco acostumbradas a comunicarse y relacionarse de modo regular, por lo que tampoco suelen contar con el equipamiento necesario para poder abrirse.

Al hilo de lo anterior, Chevalier (1988: 252) señala que el concepto de transparencia alberga, al menos, tres tipos de significados diferentes: a) la comunicación, pues ésta despliega su lógica con el ciudadano e implica la sustitución del modelo de relación monogal por el dialogal; b) la publicidad, pues los asuntos administrativos deben abrirse a la plaza pública y deben estar sujetos a discusión, siendo ésta la regla general y, el secreto, la excepción; y c) la proximidad, con la que acercar las instituciones a la sociedad.

Por su parte, Sommermann (2010: 25), afirma que la transparencia: "es un elemento esencial en la estrategia de restablecer la confianza en el sistema democrático y de salvaguardar el Estado de Derecho en una realidad siempre más compleja”, y que su manifestación más concreta se encuentra en el grado de disponibilidad de la información pública. De ahí que la transparencia se oriente hacia el desarrollo de tres funciones específicas en democracia: a) entendida como instrumento, la transparencia debe limitar la corrupción y promover el equilibrio entre poderes; b) entendida como recurso, debe hacer posible que la ciudadanía ejercite su capacidad de influencia en el sistema político; y, c) por último, entendida la transparencia como refuerzo, debe generar bien común frente a los intereses particulares (Belmonte Martín, 2014: 350).

La transparencia es la luz con que se ilumina el poder, la lupa o el espejo en el que se ve y engrandece a la vista del ciudadano la acción de sus instituciones. Un principio de tal dimensión social y con un campo de actuación tan extenso, debe ser capaz de colmar toda pretensión ciudadana en democracia y su proceso de regeneración. La transparencia, exigible y predicable de cualquier centro de poder público, acerca el hecho político al pueblo, devolviendo en ellos el favor de su confianza prestada.

Sin embargo, un principio tan ligado al pacto de convivencia social, no ha sido siempre aplicado en la realidad de las organizaciones político-administrativas, así como garantizado en el Ordenamiento jurídico de los Estados. Encarnada en la libertad de expresión y de imprenta, la transparencia ha ido creciendo en la esfera individual del ciudadano, sin causar gran trascendencia ni adhesiones colectivas del pueblo. Superando su más que notable olvido tradicional, la transparencia irrumpe ahora $^{2}$ en el ámbito público para fijar posiciones, haciendo que las instituciones mantengan vivo su cometido social y que los ciudadanos tengan presente su papel de protagonista en el sistema político.

Concretamente, la transparencia nace a la vida jurídica de nuestro país, de manera autónoma, con la aprobación de la Ley 19/2013, de 9 de diciembre, de Transparencia, Acceso a la Información Pública y Buen Gobierno. 
La participación ciudadana en los asuntos públicos es un derecho que se debe garantizar por los poderes públicos, pero también fomentar su ejercicio desde las instituciones. La labor de las instituciones en la actualidad es mucho más profunda, pues deben tratar de redefinir el espacio público, de rememorar el interés general, de ganarse y de merecer la confianza que depositen en ellas los ciudadanos, de legitimar su actuación, de repensar la prestación del servicio público, de renovar el pacto de convivencia pacífica, en definitiva, de rehumanizar las esferas organizativas. Y es que el verdadero protagonista de toda acción pública es el ciudadano, en cuyo nombre y beneficio se ejerce el poder. Las instituciones deben servir al interés general, deben preguntarse siempre para qué llevan a cabo sus funciones, pues el depositario de sus actuaciones y de sus resultados es la sociedad en su conjunto. Para eso sirve la transparencia.

\section{La obligación institucional a la difusión activa de información pública}

La transparencia se materializa en el efectivo derecho a la información pública que tiene cualquier ciudadano, si bien puede ser ésta activa cuando las instituciones ofrecen datos a la sociedad sin requerimiento previo, o bien pasiva cuando los ciudadanos los piden con carácter previo. $\mathrm{Y}$ es que sin información, sin este recurso estratégico que fluye constantemente en todos los ámbitos de la vida, no resulta posible realizar ninguna actividad personal o profesional. Por ello, los poderes públicos deben asegurar la garantía del: "derecho de los ciudadanos a contar con una amplia y adecuada información respecto de los hechos que les permita tomar sus convicciones y participar en la discusión relativa a los asuntos públicos que afecten a la colectividad"3.

El legislador estatal y el legislador autonómico han incluido dos modalidades diferentes de acceso a los datos: a) la modalidad de suministro activo de información, como obligación institucional; y b) la modalidad de difusión pasiva, desde el derecho de acceso. Ambas modalidades deben ser contempladas por el legislador y aplicadas a la realidad, si bien el suministro activo es lo primordial en democracia, pues la transparencia comienza desde las propias instituciones, impregnando la vida de los ciudadanos y fomentando su participación en los asuntos de interés general.

Así, tal y como afirma Martín Delgado (2014: 376): "tan importante es la difusión proactiva de la información pública y el acceso individualizado a ésta, como el hecho de que una y otro se produzcan mediante el uso de formatos abiertos y de una forma estructurada (...), como una exigencia del derecho a saber". Hasta el punto de que el derecho de acceso a la información pública es considerado, por muchos autores, como un auténtico derecho fundamental. En lo que respecta a la transparencia activa, ésta ha constituido una auténtica novedad en el panorama políticoadministrativo, y supone todo un reto para los decisores públicos, pues de ellos va a depender, en mayor grado, su efectividad.

La transparencia pasiva lo constituye el derecho de acceso a la información, en virtud del cual todas las personas tienen derecho a acceder a la información

Así se postula por el Tribunal Constitucional en el Fundamento Jurídico $2^{\circ}$ de la Sentencia 219/1992, de 3 de Diciembre de 1992, en el Fundamento Jurídico $4^{\circ}$ de la Sentencia 178/1993, de 31 de Mayo de 1993 y en los Fundamentos Jurídicos $1^{\circ}$ y $4^{\circ}$ de la Sentencia 136/1994, de 9 de Mayo de 1994. 
pública ${ }^{4}$. Recuérdese, en este punto, que una de las finalidades específicas de la Ley de Transparencia estatal es, precisamente "garantizar el acceso a la información

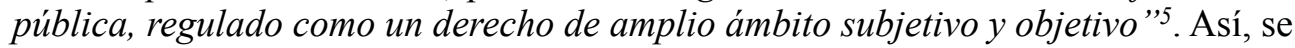
precisa una mayor implicación de las instituciones para fomentar del derecho de acceso en sus respectivos ámbitos de actuación ${ }^{6}$.

En cuanto a la normativa autonómica en materia de transparencia pasiva, Fernández Salmerón (2014:286) señala que: "el procedimiento no parece encontrar margen para una disciplina autonómica que vaya más allá de las correspondientes previsiones de desarrollo normativo", por lo que se limitan a transcribir, en sus Ordenamientos Jurídicos, aquello que ya recoge la Ley estatal.

Para el caso que nos ocupa, la modalidad que realmente nos interesa en cuanto a la visibilidad de las agendas gubernamentales es la transparencia activa. Se puede definir la transparencia activa o, lo que es lo mismo, el suministro activo de datos como la obligación de difundir, de forma permanente, periódica y actualizada, aquella información pública más relevante para garantizar la transparencia de la actividad de la Administración Pública ${ }^{7}$. Debe advertirse que, en numerosas ocasiones, en virtud de la Disposición Adicional I de la Ley 19/2013, de 9 de Diciembre, resulta difícil determinar la concreta obligación de suministro de información activa, ya que hay que estar a lo dispuesto en la normativa sectorial ${ }^{8}$.

La incorporación plena de la transparencia activa en nuestro Ordenamiento Jurídico refleja, pues, la necesidad ciudadana -y la preocupación de las instancias de gobierno-, por nutrirse de información para numerosas finalidades, entre las que se encuentra el derecho a la participación política. Hacer posible que todos los activos de información pública lleguen al ciudadano de forma paulatina, es un gran reto para la Administración Pública, pues supone cambiar muchas de sus rutinas y acostumbrarse a interconectar entre ellas de manera constante 9 .

Aunque la Ley de Transparencia estatal obliga a los sujetos a difundir información, lo cierto es que no establece ningún criterio para que las Administraciones Públicas decidan dónde publicarla pero resulta obvio pensar en la utilización de los

$4 \quad$ Según se dispone en el artículo 12 de la Ley 19/2013, de 9 de Diciembre, de Transparencia, Derecho de Acceso a la Información Pública y Buen Gobierno.

5 Tal y como se desprende de la Exposición de Motivos de dicha Ley.

$6 \quad$ No puede decirse que tal premisa sea la tenida en cuenta actualmente, pues las instituciones todavía se muestran bastante reticentes a mostrar la información. Claro ejemplo de ello es el contenido expresado en la Resolución de 3 de Diciembre de 2014, de la Presidencia del Tribunal de Cuentas, por la que se publica el Acuerdo adoptado por el Pleno en su reunión de 27 de Noviembre de 2014, sobre el derecho de acceso a la información, en donde lo único que se incluye es una mera referencia al órgano competente de tal materia en su organización interna, la preferencia de la vía electrónica en la puesta a disposición de los datos al ciudadano y la fijación de un ámbito de operaciones más restrictivo en el acceso a la información que pueda tener cualquier agente externo y que deberá regirse según lo previsto en las leyes procesales.

7 Tal y como se deduce del artículo 3.2 de la Ley de Transparencia de La Rioja.

8 Fiel reflejo de ello es el ejemplo que introduce Gómez Manresa(2014:572) en materia medioambiental, cuando señala que, en virtud de la Ley de Transparencia estatal -en concreto, del artículo 7-, resulta obligado suministrar activamente por las Administraciones Públicas información básica de relevancia jurídica y, con mayor determinación y criterio, el artículo 7 de la Ley 27/2006, de 18 de Julio, incrementa el ámbito objetivo de tal obligación al incluir, además de proyectos de ley, resoluciones, etc., programas, planes, autorizaciones, informes, etc.

9 La contratación pública constituye un claro ejemplo de cómo la transparencia genera cambios encaminados hacia la publicidad y la apertura de los procedimientos en las instituciones (Martínez Fernández, 2016). 
medios electrónico para llevar a cabo esta función de máxima publicidad de datos. Así, la Administración Electrónica se define como: "el uso de las Tecnologías de la Información y de la Comunicación en las Administraciones Públicas combinado con cambios organizativos y nuevas aptitudes, con el fin de mejorar los servicios públicos y los procesos democráticos y reforzar el apoyo a las políticas públicas "10.

Al respecto, han sido tres los factores que han hecho mejorar la disposición de información pública en los últimos años (Cobacho López, 2014:141): a) el desarrollo tecnológico, que ha ayudado a que ésta se pueda encontrar, almacenar y difundir mejor; b) la toma en consideración del valor económico que pueden generar los datos; y c) la propia revitalización de la democracia mejorando la participación pública en los asuntos de interés general.

En base a lo antedicho, el Sitio Web es el punto de encuentro inmediato del ciudadano con las instituciones o, lo que es lo mismo, su puerta de acceso directo a los e-Servicios y el que más peso adquiere en la actualidad. Tal y como se regulaba en el artículo 10.1 de la Ley 11/2007, de 22 de junio, la Sede Electrónica se define como: "aquella dirección electrónica disponible para los ciudadanos a través de redes de telecomunicaciones cuya titularidad, gestión y administración corresponde a una Administración Pública, órgano o entidad administrativa en el ejercicio de sus competencias".

Considerando que la obligación de difusión activa de datos es común a todas las instituciones político-administrativas, cada una de ellas es la que debe determinar las condiciones y los instrumentos de su creación de las Sedes Electrónicas, sujetándose a los principios de publicidad oficial, responsabilidad, calidad, seguridad, disponibilidad, accesibilidad, neutralidad e interoperabilidad. El propio establecimiento de una Sede Electrónica conlleva la responsabilidad del titular respecto de la integridad, la veracidad y la actualización de la información y de los servicios a los que pueden accederse a través de ella.

\section{La regulación de las agendas institucionales en las leyes de transparencia pública españolas}

Como se ha señalado anteriormente, el acceso a la información pública no es posible si no existe un verdadero servicio encargado de prestarla. $\mathrm{Y}$ es la trascendencia que tiene la información para el conjunto de los ciudadanos, en un sistema democrático, es lo que convierte a este servicio en obligatorio. El suministro activo de la información pública de las instituciones a los ciudadanos, no debe ser visto como una especie de dadiva que éstos primeros les ofrecen a los otros, sino como una verdadera obligación por la función social que realizan. Y es que la democracia no es más que "el Gobierno del poder público en público" (Bobbio, 1980).

La posibilidad de que los ciudadanos tengan acceso al contenido de las agendas institucionales es un reto muy fácil de conseguir y que ayudaría enormemente a la credibilidad de lo público. Además, esta información posibilita la planificación y la programación de los ejecutivos y que éstos adopten medidas de carácter preventivo

10 Tal y como versa la Comunicación 2003/567, de 26 de Septiembre, relativa al Papel de la Administración Electrónica en el futuro de Europa. 
en su gestión. En este sentido, la planificación estratégica es otro componente esencial de la regeneración democrática, pues apunta a la definición de la estrategia de los ejecutivos, junto con la definición de responsabilidades para la implementación de la misma, que le permiten dar respuesta a los nuevos problemas con los que se enfrenta en su funcionamiento cotidiano.

La estrategia es una pieza clave en democracia. En este sentido, Moore (1998: 115), habla de triángulo estratégico en la planificación pública y con ello se refiere a que la estrategia organizativa de cualquier entidad es un concepto que, simultáneamente: a) declara la misión o propósito general de la organización para con su entorno, construido éste en torno a valores públicos tan importantes como el servicio público, la colaboración, la cooperación, la solidaridad o la eficacia; b) explica las fuentes de apoyo y legitimidad que se utilizan para satisfacer el compromiso de la sociedad en dicha tarea. La estrategia debe ser políticamente sostenible, es decir, debe ser capaz de atraer a todos los agentes implicados bajo una dirección participativa; o c) explica cómo la tarea se organiza y gestiona para conseguir los objetivos, es decir, debe ser operativa y administrativamente viable, haciendo que las actividades autorizadas pueden realizarse a través de la organización existente con la ayuda de otras que pueden ser inducidas a contribuir al objetivo organizativo.

Esta planificación precisa de una reflexión profunda entre los miembros de la institución, que busca identificar lo que ésta es actualmente, con sus fortalezas y deficiencias, y lo que quiere ser en el futuro, definiendo para ello unos objetivos y metas y sus estrategias correspondientes y un cronograma temporal de actuación. Que el ciudadano cuente con esta información es muy importante para evaluar las políticas públicas y para fiscalizar la acción de gobierno.

\section{1. ¿Qué es la agenda institucional?}

El conflicto y la incertidumbre son dilemas inherentes a cualquier sociedad y los pactos y consensos de convivencia pacífica de las personas están sujetos a una revisión continua. Así, cuanto más compleja se vuelve la naturaleza humana, más intrincado se va haciendo el arte de la política, la destreza de la cohesión social, la maestría de la concordia pacífica y la persistencia de la humanidad. Pero es el individuo constituye la causa y el fin de la política, que no es más que el logro de su felicidad colectiva, "por lo que consecuentemente, en el Estado, es sobre todo el ciudadano, $y$ en menor medida las instituciones, las que determinan el acontecer político" (Roche Cárcel, 2013:19).

Por eso se hace necesario introducir cambios, modernizar con sentido, redefinir el autogobierno democrático (Archibugi, 2008; Sandel, 2008), fomentar la coordinación e interdependencia de las organizaciones públicas (Börzel, 1998), posibilitar la participación ciudadana (Fleury, 2002: 236), autolimitar el poder público mediante la transparencia (Fukuyama, 2005: 73). Así, las fuentes del riesgo en el ámbito público ya no residen en la ignorancia sino en el saber difuso, y tampoco se sitúan en el dominio deficiente de su naturaleza sino en su dominio perfeccionado, lo que genera irresponsabilidad organizada (Beck, 1998).

Sin embargo, en sociedades cada vez más plurales y complejas, los problemas van adquiriendo mayor amplitud y complicación, por lo que el cuerpo de conocimiento de la disciplina se torna más incierto y voluble. El conflicto social aumenta 
en un escenario cada vez más globalizado y complejo, en el que proliferan mayores y más diversificadas demandas sociales a las que se pide una solución política común.

Pese a que el conflicto social ha existido siempre y en toda época histórica, no han sido constantes los cleavages $^{11}$, las diferencias y desigualdades que han movido a la acción pública, los desequilibrios, las incertidumbres, los riesgos, las resistencias, las expectativas, las reivindicaciones de los ciudadanos. Del mismo modo, no todos los problemas que han preocupado a la sociedad en un momento determinado -lo que se denomina agenda sistémica- han ocupado la atención de los decisores políticos, convirtiéndose en verdaderas prioridades de actuación pública -lo que se denomina agenda institucional o de gobierno- (Tamayo Sáez, 1997: 289). La política es precisamente eso, la elección de conflictos sociales que, en un momento determinado, desean solucionar las instituciones adoptando decisiones vinculantes que aporten un seguro colectivo, un agregado compartido, una construcción de la vida en colectividad.

Por agenda institucional podemos entender la relación ordenada y temporalizada de compromisos, asuntos y actividades que ha de hacer, que ha de tratar el Poder Ejecutivo, sea éste del nivel territorial que sea. Conocer esta información puede resultar de mucho interés para la sociedad, para los medios de comunicación, para los empresarios, para los profesionales, etc., pues en la agenda se marcan las preferencias temáticas y secuenciales de los asuntos de interés general. Ordenar las prioridades de acción de los ejecutivos correctamente, presupuestar específicamente sus actividades, delimitar tiempos de trabajo y equipos o visibilizar la actividad de gobierno o son cuestiones fundamentales cuando queremos repensar nuestro modelo actual de democracia.

Pero, ¿qué actores deben visibilizar su actividad? ¿Sólo el gobierno o también la Administración Pública? No cabe la menor duda de que la Administración Pública es una institución plena, dotada de poder público, que está adquiriendo cada vez más notoriedad y significación. Es ésta la institución más cercana al ciudadano, la que comunica el sistema político con el sistema social, la que almacena y da respuesta a las demandas sociales y la que está más capacitada para adoptar las decisiones políticas. Olías de Lima-Gete (1977:93-94) se hace eco de esta visión y afirma que: "la Administración se ha transformado en el poder predominante dentro del aparato estatal, asumiendo no pocas de las funciones que antes estaban reservadas a otros órganos del Estado". Por todo ello, la Administración Pública es el exponente institucional de mayor relevancia en el estudio de la política como actividad que asegura la convivencia social y debe ser un actor obligado a facilitar su programación.

Así, tal y como establece la Ley 19/2013, de 19 de Diciembre en su artículo 2.1.a), el primero de los sujetos obligados a la transparencia activa $-y$, por nuestro razonamiento, a la difusión de su agenda-, son las Administraciones Públicas, toda vez que éstas, cumplen con una labor encomiable de servicio público y, además, son las más cercanas al ciudadano, son las que mejor pueden informar de las decisiones de gobierno e informarse de las demandas sociales que deben ser resueltas. En este

11 Por cleavages - clivajes o escisiones-, entendemos las líneas de conflicto social latentes en determinadas sociedades, que influyen en el comportamiento electoral y en el sistema de partidos, como pueden ser: la división de clases sociales, la diferencia de género o la distinción entre élite y masa, entre otras (Lipset y Rokkan, 1967). 
sentido, Rodríguez-Arana Muñoz (2007: 29) manifiesta que "los ciudadanos son legitimamente los dueños del aparato administrativo y tienen legitimo derecho a conocer las razones de su actuación y la forma en que se producen sus declaraciones de voluntad o juicio sobre las más diversas cuestiones", porque la Administración está investida de poder público y cumple, además de una función social, una dimensión política.

Al efecto de esta Ley, se entiende por Administración Pública ${ }^{12}$ la denominada Administración territorial, la cual abarca, a su vez: la Administración General del Estado, la Administración de las Comunidades y las Ciudades Autónomas y la Administración Local, tanto municipal como provincial. ${ }^{13}$ En base a lo antedicho, todos estos órganos estarían en la obligación de facilitar su agenda institucional, en tiempo y forma, para que sea conocida por la ciudadanía.

Lo que cabe preguntarse, en este punto, es si el gobierno -ya sea ésta central o autonómico-, que es quien "dirige la Administración civil del Estado"14, queda o no incluido en el ámbito subjetivo -tanto activo como pasivo-, de la Ley de Transparencia. La Administración Pública, siendo dirigida por el Gobierno, consideramos que éste último, pese a no incluirse expresamente en el articulado de la $L e y^{15}$, se sobreentiende que también debe cumplir ${ }^{16}$ con las obligaciones de transparencia activa y pasiva (Pendás, 2013) y, por tanto, con el deber de difusión de la agenda institucional de los órganos que lo componen.

A su vez, quizás hubiera sido interesante incluir el término de "autoridad públi$c a^{" 17}$ a la hora de fijar el ámbito subjetivo de aplicación de la Ley. para obligar a la transparencia activa $-\mathrm{y}$, por ende, a la difusión de las agendas-, a cualquier sujeto que asuma responsabilidades públicas, que ejerza funciones públicas o que preste servicios públicos, con cierto grado de importancia e interés general. Como sostiene Alonso Timón (2012:34), "la aplicación del principio de transparencia a la actuación de todos los poderes públicos en la actualidad es una cuestión irreversible, irrenunciable e indiscutible", por lo que, siendo predicable de cualquier poder público, es también asumible en todos los ámbitos de la sociedad.

Por último, es necesario poner de manifiesto que los activos de información pública carecen de valor alguno si no se difunden en el tiempo adecuado y en la forma correcta. La ingente cantidad de datos que se producen y se reproducen, pue-

12 Tal y como señala Canales Aliende (2014a:141), la Administración Pública, por su carácter institucional, asegura "la continuidad de la acción gubernamental y de las políticas públicas, siendo un instrumento esencial ante todo para el servicio de la ciudadania". Por ello, por el servicio público que presta a la sociedad, debe ofrecer la más amplia información sobre la actuación que realiza y sobre los resultados que consigue, pues de ello depende su legitimidad.

13 En este sentido, también se incluirían los entes señalados en el artículo 3.2 de la Ley 7/1985, de 2 de Abril, de Bases de Régimen Local, esto es, "las Comarcas u otras entidades que agrupen varios Municipios, instituidas por las Comunidades Autónomas de conformidad con esta Ley y los correspondientes Estatutos de Autonomía; b) Las Áreas Metropolitanas; y c) Las Mancomunidades de Municipios".

14 Así queda de manifiesto en el artículo 97 de la Constitución Española de 1978 o en el artículo 1.1 de la Ley 50/1997, de 27 de noviembre, del Gobierno.

15 No ocurre lo mismo con el artículo 1.2.a) del Convenio $n^{\circ} 205$ del Consejo de Europa, de 18 de Junio de 2009, sobre el Acceso a los Documentos Públicos, ya que éste incluye expresamente como autoridades públicas al "1) gobierno y administración a nivel nacional, regional y local; 2) organismos legislativos y autoridades judiciales, en cuanto realizan funciones administrativas según la normativa nacional propia; $y$ 3) personas naturales o jurídicas cuando ejercen como una autoridad administrativa". A su vez, es de reseñar que ninguna legislación autonómica, aprobada o en trámite parlamentario, incluya explícitamente al Gobierno en su ámbito subjetivo. 
den generar problemas de intoxicación informacional, de infoxicación (Cornella Solans, 2001:126). Por ello, dicho autor, cree necesario establecer ciertos atributos básicos que aseguren la calidad en la información contenida en las agendas y éstos son los siguientes: a) fiabilidad, entendida como la confianza del usuario en la fuente informativa; b) puntualidad, a modo de adecuación temporal entre la obtención de la información y la necesidad de quien la adquiere; c) detalle, como la adecuación entre la cantidad y el fin de ésta; d) accesibilidad, para facilitar que ésta se encuentre en formato sencillo; e) relevancia, para que la información debe servir para solucionar un problema concreto; f) adecuación, por cuanto ésta sirva para la finalidad requerida; g) exhaustividad, para que se muestre lo más completa posible; h) precisión, para que la información se ajuste a la petición de su requerimiento; i) direccionamiento, para que llegue a quien la ha pedido; j) comunicabilidad, para que se produzca a través de un canal concreto; y k) comprensibilidad, para que la entienda quien deba utilizarla.

\subsection{Las agendas institucionales en la normativa autonómica}

Tal y como sostiene Canales Aliende (2013:16): "sin información no hay transparencia, y sin ésta no es posible el control, y sin el control no se puede exigir, y por tanto no hay democracia". La posibilidad de acceder a la información que arrojan las agendas institucionales es una cuestión trascendental en la regeneración de la democracia. Si la sociedad conoce, con exhaustividad y detalle, la actividad diaria que desempeñan sus decisores públicos, mayor es su posibilidad de participar en política, más fiscalización puede ejercer sobre sus representantes y más confianza puede mostrar hacia las instituciones.

En primer lugar, es preciso destacar que, en una búsqueda rápida por los Sitios Web del ejecutivo estatal y de los autonómicos observamos que, desde las Consejerías de Presidencia, se ofrece esta información de agenda a los ciudadanos. Pero debemos advertir que los datos no son regulares en el tiempo, que en numerosas ocasiones la información que se facilita no coincide con la programación posterior de los eventos, que las actividades están desactualizadas y que el contenido de las citas de las agendas es demasiada escueto y sin informes que profundicen en los asuntos que van a tratarse en cada evento programado. A continuación, profundizaremos sobre la normativa que regula esta materia.

En concreto, las leyes de transparencia pública españolas -sean éstas la estatal o las autonómicas-, son aquellas que regulan la publicidad activa de la información, reconocida como tal aquella que están obligadas a mostrar las instituciones para que el ciudadano la conozca en tiempo y forma. En este sentido, es en los preceptos de tales normas donde debemos buscar si el legislador ha recogido o no, como información obligada, el contenido de las agendas de los ejecutivos.

16 Nótese que del actualmente derogado artículo 37.5.a) de la Ley 30/1992, de 26 de Noviembre, parecía entenderse que era ya obligatoria la publicidad de la información sobre actuaciones del Gobierno en el ejercicio de sus competencias sujetas a Derecho Administrativo. Consideramos que tanto los actos administrativos como los actos políticos deben ser de obligada publicidad - pues ambos emanan de autoridad pública-, sin más excepciones que las propias impuestas por el legislador con carácter general.

17 A tal término aluden la Ley 27/2006, de 18 de Julio y el Convenio ${ }^{\circ} 205$ del Consejo de Europa. 
Comenzando por la general y común a todo el Estado, la Ley 19/2013, de 9 de Diciembre, de Transparencia, Acceso a la Información Pública y Buen Gobierno, distingue tres clasificaciones de información pública: a) la institucional, la organizativa y la de planificación: b) la información de relevancia jurídica; y c) la información económica, presupuestaria y estadística. Lo lógico sería pensar que esta ley incluyera, en el apartado a), la obligación de publicidad activa de la agenda de los ejecutivos, ya que la información institucional, organizativa y de planificación alude a aquella que se conoce como información de servicio, pues a través de ésta los ciudadanos pueden acceder al conocimiento de sus derechos y obligaciones y a la utilización de los bienes y servicios públicos (Soto Lostal, 2011). Sin embargo, el artículo 6 de la Ley 19/2013 omite la obligación de publicitar las agendas de los ejecutivos.

En lo que respecta a las Comunidades Autónomas ${ }^{18}$, y tal y como pone de manifiesto Guichot Reina (2012:134), su margen de actuación para decidir la amplitud de las leyes de transparencia en su ámbito territorial es bastante extenso. Hasta el momento, casi todas las Autonomías cuentan con una normativa propia en materia de transparencia pública. Sin embargo, de las que sí cuentan con normativa, sólo cinco reconocen la obligación específica de los ejecutivos de publicar su agenda. A continuación se detallan cuáles son y cómo regulan tal materia.

En primer lugar, la Ley 1/2014, de 24 de junio, de Transparencia Pública de Andalucia, en su artículo 10.1.m), recoge la obligación de publicar las agendas institucionales de los gobiernos, entendida esta información como una subcategoría de la información institucional y organizativa de los sujetos obligados. Esta Comunidad Autónoma considera la publicidad activa en su máxima expresión, favoreciendo así que la ciudadanía conozca la información que sea relevante para garantizar su actitud proactiva y la transparencia en su actividad.

18 Cronológicamente, del modo que sigue a continuación: *Ley 4/2006, de 30 de junio, de Transparencia y Buenas Prácticas en la Administración Pública Gallega (publicada en el Diario Oficial de Galicia $\mathrm{n}^{\circ}$ 136, de 14 de julio de 2006); *Ley 4/2011, de 31 de marzo, de Buena Administración y Gobierno de Illes Balears (publicada en el Boletín Oficial de Illes Balears n ${ }^{\circ} 53$, de 9 de abril de 2011); *Ley 4/2013, de 21 de mayo, de Gobierno Abierto de Extremadura (publicada en el Diario Oficial de Extremadura $n^{\circ} 99$, de 24 de mayo de 2013); *Ley Foral 11/2012, de 21 de junio, de Transparencia y del Gobierno Abierto de Navarra (publicada en el Boletín Oficial de Navarra ${ }^{\circ} 125$, de 28 de junio de 2012); *Ley 1/2014, de 24 de junio, de Transparencia Pública de Andalucía (publicada en el Boletín Oficial de la Junta de Andalucía $\mathrm{n}^{\circ} 124$, de 30 de junio de 2014); *Ley 3/2014, de 11 septiembre, de Transparencia y Buen Gobierno de La Rioja (publicada en el Boletín Oficial de La Rioja n ${ }^{\circ} 115$, de 17 de septiembre de 2014); * Ley 12/2014, de 16 de diciembre, de Transparencia y Participación de la Comunidad Autónoma de la Región de Murcia (publicada en el Boletín Oficial de la Región de Murcia n ${ }^{\circ} 290$, de 18 de diciembre de 2014); *Ley 12/2014, de 26 de diciembre, de Transparencia y Acceso a la Información Pública de Canarias (publicada en Boletín Oficial de Canarias $n^{\circ}$ 5, de 9 de Enero de 2015); *Ley 19/2014, de 29 de diciembre, de Transparencia, Acceso a la Información y Buen Gobierno de Cataluña (publicada en el Diari Oficial de la Generalitat de Catalunya ${ }^{\circ}$ 6780, de 31 de diciembre de 2014); *Ley de Transparencia y Participación Ciudadana de Castilla y León (publicada en el Boletín Oficial de Castilla y León $\mathrm{n}^{\circ}$ 49, de 12 de Marzo de 2015); *Ley 2/2015, de 2 de abril, de Transparencia, Buen Gobierno y Participación Ciudadana de la Comunitat Valenciana (publicada en el Diari Oficial de la Comunitat Valenciana $\mathrm{n}^{\circ} 7500$, de 8 de abril de 2015); *Ley 8/2015, de 25 de marzo, de Transparencia de la Actividad Pública y Participación Ciudadana de Aragón (publicada en el Boletín Oficial de Aragón n ${ }^{\circ} 68$, de 10 de abril de 2015); y *Ley 4/2016, de 15 de diciembre, de Transparencia y Buen Gobierno de CastillaLa Mancha (publicada en el Diario Oficial de Castilla.-La Mancha $n^{\circ} 252$, de 30 de diciembre de 2016). Asturias, Cantabria, Madrid y País Vasco son las cuatro Autonomías que aún no han regulado esta materia en sus respectivos ámbitos de actuación pero en plena tramitación de estos proyectos normativos. 
El artículo 14.1.i) de la Ley 12/2014, de 16 diciembre, de Transparencia y Participación Ciudadana de la Comunidad Autónoma de la Región de Murcia, regula que las agendas institucionales de que tengan en el ejercicio de sus funciones, aquellos que, de acuerdo con la normativa en materia de altos cargos existente en la Administración Regional, tengan tal consideración, y, específicamente, a los máximos órganos directivos de su sector público, a aquellas personas que ejerzan la máxima responsabilidad en las entidades siempre que ejerzan sus funciones en régimen de dedicación plena y exclusiva al servicio público, sean remunerados por ello y estén sometidos al régimen de incompatibilidades y conflictos de intereses de la legislación autonómica sobre el alto cargo público, se deben mantener públicas al menos durante un año.

Por su parte, la Ley 19/2014, de 29 de diciembre, de Transparencia, Acceso a la Información y Buen Gobierno de Cataluña reconoce en el artículo 55.1.c) la transparencia de las actividades oficiales, de los actos y decisiones relacionados con la gestión de los asuntos públicos que tienen encomendados y de su agenda oficial, a efectos de publicidad del Registro de grupos de interés, y como un principio básico de actuación de los altos cargos del gobierno. De este modo, se pone de manifiesto cómo publicitar la agenda institucional ayuda a que el ciudadano fiscalice la acción gubernamental.

La Ley 8/2015, de 25 de marzo, de Transparencia de la Actividad Pública y Participación Ciudadana de Aragón, dedica un apartado específico de la normativa a regular la transparencia política y los datos que, dentro de ella, deben publicitarse. En concreto, el artículo 13.5.a) señala que las agendas de actividad institucional de los miembros del Gobierno y de los altos cargos, se tienen que mantener públicas, como mínimo, durante todo su mandato. Y en el caso en que no pueda hacerse pública la agenda con carácter previo, la publicidad se hará a posteriori, salvo que existan causas justificadas que lo impidan. Considero una gran aportación la que realiza en legislador aragonés, pues reitera la necesidad de hacer visible la agenda antes o después de que as actividades se lleven a cabo, si bien sería mucho más conveniente con anterioridad.

El artículo 9.5.f) de la Ley 2/2015, de 2 abril, de Transparencia, Buen Gobierno y Participación Ciudadana de la Comunitat Valenciana sostiene la obligación de publicidad activa de las agendas institucionales de las personas integrantes del Consell y sus altos cargos.

Por último, el artículo 9.3 de la Ley 4/2016, de 15 de diciembre, de Transparencia y Buen Gobierno de Castilla-La Mancha, regula que la Administración de la Junta de Comunidades de Castilla-La Mancha y sus organismos y entidades de derecho público vinculados o dependientes así como el resto de entes que configuran el sector público regional publicarán, además, las agendas de trabajo de los titulares de los órganos directivos, de apoyo o asistencia. A su vez, el artículo 35.2 de la citada Ley señala que los miembros del gobierno adecuarán su actividad al principio de transparencia en las agendas y actividades oficiales. De igual modo, el artículo 50.1.c) de la Ley refleja la responsabilidad de los altos cargos o asimilados por una serie de infracciones tipificadas, cuando las conductas se refieran a la llevanza de sus agendas.

Como nota destacable, es preciso apuntar que las Entidades Locales también han comenzado a regular la transparencia en sus respectivos ámbitos territoriales y, algunas de ellas, incluyen la agenda del ejecutivo como información de obligada difusión para las instituciones. Ejemplo de ello es la Ordenanza sobre Transparencia y 
Libre Acceso a la Información de Zaragoza que, en su artículo $20 \mathrm{~m}$ ), señala que la agenda del alcalde, de los miembros del Gobierno, de los portavoces de los grupos políticos y del resto de los miembros de la corporación, ha de hacerse visible.

La realidad normativa nos muestra que aún queda mucho camino por recorrer para lograr la plena y efectiva difusión de las agendas institucionales para que éstas sean conocidas por los ciudadanos y para que mejore la planificación de los centro de poder público. Sin conocer la programación actualizada de las actividades gubernamentales, es más complicado asegurar la imparcialidad ${ }^{19}$, la independencia ${ }^{20}$ y la neutralidad ${ }^{21}$ de las instituciones político-administrativas en nuestro país. En palabras de Aguiar González (2013:250) realiza un estudio de cómo afecta el análisis institucional a las decisiones imparciales, llegando a la conclusión de que dicha imparcialidad queda restringida por: a) la falta de claridad respecto de las posiciones que ocupan los actores en los procesos de decisión; b) la falta de información sobre acciones y resultados; y c) los intereses privados de los actores y el coste que les supone renunciar a esos intereses.

Hablar de Gobierno Abierto supone repensar la Administración Pública y el Gobierno, un cambio de ideas, de valores, en definitiva, supone un cambio integral desde la transparencia, un cambio cultural, pues es imprescindible conocer el objetivo que persiguen cada una de las instituciones que debe ser, en todo momento, prestar el mejor servicio al ciudadano (Calderón y Lorenzo, 2010). Por eso es trascendental que la sociedad pueda obtener información permanente sobre los procesos, los medios y los resultados que rigen la acción pública, sobre la planificación y programación de las actividades de las organizaciones. Y por eso resulta vital conocer, a fecha real, el contenido de las agendas institucionales.

Pero no debemos esperar a que el cambio se materialice sólo, ya que: "la transparencia necesita dos ingredientes esenciales. Sin una verdadera voluntad politica de querer ser transparentes, las leyes no sirven para nada. Y sin una auténtica exigencia ciudadana de querer saber, tampoco se puede esperar que los poderes públicos se esmeren mucho en ser transparentes" (Blanes Climent, 2014:43). Ciudadanos e instituciones tenemos un gran reto por delante si queremos fortalecer nuestra convivencia pacífica.

\section{Conclusiones}

Primera.- El principio esencial para regenerar la democracia es la transparencia pública, ya que facilita la apertura de los procesos, de los medios y de los resultados de las instituciones político-administrativas y es un remedio contra la corrupción y contra la desafección social por los asuntos de interés general. La transparencia pública brinda una oportunidad idónea a los representantes que ejercen el poder público, para que certifiquen esa confianza que les han otorgado los ciudadanos en la búsqueda de la cohesión y de la minimización del conflicto social. La transpa-

19 La imparcialidad puede entenderse como la falta de designio anticipado en favor o en contra de alguien o de algo, que permite proceder con rectitud.

20 La independencia puede entenderse como la no dependencia de otros, sostener una actividad sin admitir intervención ajena.

21 La neutralidad puede entenderse como la no participación en ninguna opción susceptible de conflicto. 
rencia es la luz con que se ilumina el poder público, la lupa que engrandece a la vista del ciudadano la acción de sus instituciones. Así, la transparencia irrumpe ahora con fuerza en el ámbito público, haciendo que las instituciones mantengan vivo su cometido social y que los ciudadanos tengan presente su papel de protagonista en el sistema político.

Segunda.- La manifestación más característica de la transparencia, como principio vertebrador del Estado de Bienestar, es el derecho a la información, en términos generales y a la información pública, de manera concreta. Unido a ello, los ciudadanos, tienen reconocido, en su estatuto subjetivo de derechos, el de acceder y de disponer de información pública. De este modo, mientras que el derecho de acceso requiere una iniciativa ciudadana de acción y una posición institucional pasiva, el derecho de recibir información precisa de una iniciativa ciudadana de reacción y una posición institucional activa para su difusión. Por ello, en materia de información, más que el acceso como derecho de libertad personal del ciudadano, es necesario apostar por la disposición de datos de las instituciones como una obligación de ellas $\mathrm{y}$ un derecho prestacional para la sociedad.

Tercera.- De lo anterior se deduce que la obligación institucional de publicar las agendas de los ejecutivos en España debe ser una materia que encuentre su regulación en las leyes de transparencia. Si bien el Estado no ha considerado esencial incluir en la normativa de referencia la publicidad de estas agendas desde la obligación a la difusión activa de la información por parte de las instituciones, algunas Comunidades Autónomas sí que lo regulan (sobre todo aquellas que están aprobando sus leyes más recientemente). Del contenido exacto de tal regulación vemos cómo la tónica general reside, sobre todo, en el reconocimiento explícito de las Autonomías de la obligación, pero no tanto en la aplicación efectiva, actualizada y puntual de los datos y calendarios de las agendas a través de los Sitios Web de las instituciones. Ya es plausible su concreción legislativa, pero aún queda una importante labor por realizar para que la difusión de la agenda de los ejecutivos sea un hecho natural y cotidiano en el sistema político.

\section{Bibliografía}

Aguiar González, F. (2013). "Análisis Institucional y decisiones imparciales”, en Carlos Arias Moreira, X y Caballero Mínguez, G. (eds.). Nuevo Institucionalismo: Gobernanza, Economía y Políticas Públicas. Centro de Investigaciones Sociológicas, Madrid, pp. 231-250.

Aldeguer Cerdá, B. (2013). "La transparencia como principio e indicador para la mejora de la calidad democrática", en Bañón i Martínez, R. y Tamboleo García, R. (coords.). Gestión de la escasez: Participación, territorios y Estado del Bienestar. Experiencias de democracia y participación. GOGEP Complutense, Madrid, pp. 342-246.

Alonso Timón, A. J. (2012). "El principio de transparencia como elemento vertebrador del Estado Social y Democrático de derecho", en Asamblea, n. 27, pp.27-62. Archibugi, D. (2008). The Global Commonwealth of citizens: Towards Cosmopolitan Democracy. Princeton University Press, Princenton.

Argentina. Organización de las Naciones Unidas. (2004). La democracia en América Latina: hacia una democracia de ciudadanas y ciudadanos. PNUD, Buenos Aires. 
Beck, U. (1998). "Politics of risk society", en Franklin, J. (ed.). The politics of risk society. Policy Press, Londres.

Bellver Vázquez-Dodero, A. (2007). "Reformas en materia de transparencia: segunda generación de cambio institucional", en Revista Reforma y Democracia, n. 38, pp. 1-28.

Belmonte Martín, I. (2014). "transparencia, el buen gobierno y la rendición de cuentas”, en Canales Aliende, J. M. y Sanmartín Pardo, J. J. (eds.). Introducción a la Ciencia Política. Editorial Universitas S.A, Madrid, pp. 347-373.

Blanes Climent, M. A. (2014). La transparencia informativa de las administraciones públicas. El derecho de las personas a saber y la obligación de difundir información pública de forma activa. Aranzadi, Pamplona.

Bobbio, N. (1980). La democracia y el poder invisible. Plaza \& Janés, Barcelona.

Börzel, T. (1998). "Organizing Babylon-on the different conceptions of policy networks?", en Public Administration, n. 46, pp. 253-273.

Calderón, C. y Lorenzo, S. (2010). ¿Qué es Gobierno Abierto? Open Government: Gobierno Abierto. Algodón Editores, Jaén.

Canales Aliende, J. M. (2013). "Algunas nuevas reflexiones sobre la gobernanza", en Deliberación, n. 3, pp. 9-19.

- (2014). "El Poder Ejecutivo", en Canales Aliende, J. J. y Sanmartín Pardo, J. J. (eds.). Introducción a la Ciencia Política. Editorial Universitas S.A, Madrid, pp. 131-141.

Chevalier, J. (1988). "Le mythe de la transparence administrative", en Brachet, P., Beynoix, A y Hénry-Meinieger, M.C. (eds.). Information et transparence administratives. Presses Universitaires de France, Paris, pp. 239-275.

Cobacho López, A. (2014). "Transparencia y poder legislativo", en Valero Torrijos, J y Fernández Salmerón, M. (coord.), Régimen jurídico de la transparencia del sector público: Del Derecho de acceso a la reutilización de la información. Aranzadi, pp. 135-158,

Cornella Solans, A. (2001). Infonomía.com. La gestión inteligente de la información en las organizaciones. Ediciones Deusto, Bilbao.

Fernández Salmerón, M. (2014). "Procedimiento administrativo e información del sector público", en Valero Torrijos, J y Fernández Salmerón, M. (coord.). Régimen jurídico de la transparencia del sector público: Del Derecho de acceso a la reutilización de la información. Aranzadi, Madrid, pp. 281-321.

Florini, A. (1999). Does the invisible hand need a transparency glove? The politics of transparency. Paper presented at the Annual World Bank Conference on Development Economics, Washington D.C., United States of America.

Fukuyama, F. (2005). State building governance et ordre du monde au xxième siècle. La Table Ronde, Paris.

Garde Roca, J. A. (2004). "La evaluación de políticas y su institucionalización en España", en Gestión y Análisis de Políticas Públicas, n. 30-31, pp. 11-28.

Gómez Manresa, Ma . F. (2014). "El acceso a la información en materia de ordenación del territorio y urbanismo", en Valero Torrijos, J y Fernández Salmerón, M. (coord.). Régimen jurídico de la transparencia del sector público: Del Derecho de acceso a la reutilización de la información. Aranzadi, Madrid, pp. 559-585.

Guichot Reina, E. (2012). "El proyecto de Ley de Transparencia y Acceso a la Información Pública y el Margen de Actuación de las Comunidades Autónomas", en Administración de Andalucía, n. 84, pp. 89-134. 
Lipset, S. M. y Rokkan, S. (1967). Party systems and voter alignments: Cross-national perspectives. Free Press, Ney York.

Martín Delgado, I. (2014). "Transparencia, reutilización y datos abiertos. Algunas reflexiones generales sobre el acceso libre a la información pública”, en Valero Torrijos, J y Fernández Salmerón, M. (coord.), Régimen jurídico de la transparencia del sector público: Del Derecho de acceso a la reutilización de la información. Aranzadi, Madrid, pp. 367-406.

Martínez Fernández, J. M. (2016). Contratación pública y transparencia. El Consultor de los Ayuntamientos, Madrid.

Moore, M. H. (1998). Gestión estratégica y creación de valor en el Sector Público. Paidós, Barcelona.

Olías de Lima-Gete, B. (1977). "La Ciencia de la Administración en España”, en Documentación Administrativa, n. 176, pp. 91-110.

Pasquier, M. y Villeneuve, J.P. (2007). "Barreras de la organización a la transparencia. Una tipología y análisis del comportamiento de la organización tendente a prevenir o restringir el acceso a la información", en Revista Internacional de Ciencias Administrativas, n. 1, pp. 169-186.

Pendás García, B. (2013). "Comparecencia para informar en relación con el Proyecto de Ley de Transparencia, Acceso a la Información Pública y Buen Gobierno", en Diario de Sesiones del Congreso de los Diputados, 301, X Legislatura.

Roche Cárcel, J. A. (2013). "La frágil construcción de la democracia en la Grecia Antigua y la búsqueda del orden en la teoría democrática moderna y contemporánea”, en Res Pública: Revista Filosofia Pública, n. 30, pp. 15-58.

Rodríguez-Arana Muñoz, J. (2007). "Sobre la transparencia en la administración pública", en Revista de Estudios Locales, n. 103, pp. 28-39.

Sandel, M. J (2006). Public philosophy: Essays on morality in politics. Harvard University Press, Boston.

Saramago, J. (2004). Ensayo sobre la lucidez. Alfaguara, Madrid.

Sommermann, K. P. (2010). "La exigencia de una administración transparente en la perspectiva de los principios de democracia y del Estado de Derecho", en García Macho, R. J. (coord.). Derecho Administrativo de la Información y Administración Transparente. Madrid: Marcial Pons, Madrid, pp. 7-26.

Soto Lostal, S. (2011). El derecho de acceso a la información, el Estado Social y el Buen Gobierno. Tirant Lo Blanch, Valencia.

Tamayo Sáez, M. (1997). "El análisis de las políticas públicas”, en Bañón Martínez, R y Carrillo Barroso, E. (comp.). La Nueva Administración Pública. Alianza Editorial S.A, Madrid, pp. 281-312. 
